\title{
UM ESTUDO SOBRE O GERENCIAMENTO DOS RESÍDUOS SÓLIDOS DE SERVIÇOS DE SAÚDE NA LIGA NORTE RIOGRANDENSE CONTRA O CÂNCER
}

\author{
Ricardo Henrique Vieira de Melo \\ Mestre em Saúde da Família (RENASF/UFRN). E-mail: ricardohvm@gmail.com \\ Rose Mary Alves de Lima Melo \\ MBA em Logística (UNP), Núcleo de Logística da Liga Norte Riograndense Contra o \\ Câncer (LNRCC). E-mail: roselimamelo@ hotmail.com \\ Rodrigo Otávio Freire de Melo \\ Mestre em Administração, Docente (UNP). E-mail: rodrigomelo10@gmail.com \\ Giovanni Rêgo \\ Biólogo da Liga Norte Riograndense Contra o Câncer (LNRCC). \\ E-mail: giovannisrego@gmail.com \\ Rosana Lúcia Alves de Vilar \\ Doutora em Ciências Sociais (UFRN), Docente (RENASF/UFRN). \\ E-mail: rosanaalvesrn@gmail.com
}

\begin{abstract}
RESUMO
A geração de resíduos pelas diversas atividades humanas, incluindo os hospitalares, constitui-se atualmente em um grande desafio. No Brasil, órgãos como a Agência Nacional de Vigilância Sanitária (ANVISA) e o Conselho Nacional do Meio Ambiente (CONAMA) têm assumido o papel regulador, definindo regras e condutas adequadas aos diferentes agentes, quanto à geração e ao manejo dos diferentes resíduos, bem como o da responsabilização do gerador. Dentro desta problemática, este artigo aborda as particularidades da Liga Norte Riograndense Contra o Câncer (LNRCC), em relação ao gerenciamento dos Resíduos dos Serviços de Saúde (RSS), com o objetivo de conhecer o processo de gestão de resíduos.
\end{abstract}

PALAVRAS-CHAVE: Resíduos sólidos. Logística Reversa. Sustentabilidade.

\section{A STUDY ON SOLID WASTE MANAGEMENT OF HEALTH SERVICES IN NORTH RIOGRANDENSE LEAGUE AGAINST CANCER}

\begin{abstract}
The generation of waste by various human activities, including the hospital waste, constitutes a major challenge. In Brazil, government agencies such as the National Agency for Sanitary Surveillance (ANVISA) and the National Council for the Environment (CONAMA) have assumed the role of regulator, setting rules and behaviors appropriate to the various agents, as the generation and handling of different waste and the accountability of the generator.
\end{abstract}

PALAVRAS-CHAVE: Solid Waste. Reverse Logistics. Sustainability. 


\section{UM ESTUDO SOBRE O GERENCIAMENTO DOS RESÍDUOS SÓLIDOS DE SERVIÇOS DE SAÚDE NA LIGA NORTE RIOGRANDENSE CONTRA O CÂNCER}

\section{INTRODUÇÃO}

A geração de resíduos pelas diversas atividades humanas constitui-se atualmente em um grande desafio. Com o desenvolvimento industrial, a partir da segunda metade do século XX, sua produção vem crescendo constantemente inclusive ultrapassando a capacidade de absorção da natureza. Somado a essa questão, tem-se o aumento da diversidade dos seus componentes, pela presença de materiais de maior toxidez e de difícil degradação. $O$ descarte inadequado desses resíduos pode causar danos ambientais capazes de colocar em risco a qualidade de vida da população e comprometendo os recursos naturais do planeta.

No Brasil, órgãos como a Agência Nacional de Vigilância Sanitária (ANVISA) e o Conselho Nacional do Meio Ambiente (CONAMA) têm assumido esse papel, definindo regras e condutas adequadas aos diferentes agentes, quanto à geração e ao manejo desses resíduos e da responsabilização do gerador. A Resolução CONAMA No 005/1993 define resíduos nos estados sólidos e semissólidos os que são originados das atividades de origem industrial, doméstica, hospitalar, comercial, agrícola e de serviços de varrição.

Atualmente o gerenciamento integrado dos resíduos de serviços de saúde vem se constituindo objeto de debates, estudos e pesquisas pelo desafio inclusive da operacionalização de sistemas especificamente adequados a cada tipo de organização, independente de sua natureza ou tamanho. Desta forma, este gerenciamento é formado por procedimentos de gestão, planejados e implementados a partir de bases científicas e técnicas, normativas e legais, com o objetivo de minimizar a produção de resíduos e proporcionar, aos resíduos gerados, um encaminhamento seguro, de forma eficiente, visando à proteção dos trabalhadores, a preservação da saúde, dos recursos naturais e do meio ambiente.

Dentro desta problemática, ciente dos desafios para enfrentamento dos problemas relacionados à geração de resíduos sólidos urbanos, este artigo pretende abordar as particularidades da Liga Norte Riograndense Contra o Câncer (LNRCC), em relação ao gerenciamento dos Resíduos dos Serviços de Saúde. As investigações neste campo do conhecimento são relevantes na medida em que o volume de resíduos nos depósitos apresenta tendência de crescimento, aumentando custos inclusive relacionados à disponibilidade de áreas ambientalmente seguras para recebimento. Neste sentido, a gestão integrada desses resíduos assume papel fundamental para que seja possível um desenvolvimento sustentável.

\section{REFERÊNCIAL TEÓRICO}

\section{- LOGÍSTICA}


Sabe-se que ao longo do tempo a atividade logística compreendeu os vários ramos das atividades industriais e de operação. Porém e visto também que esta atividade, dita operacional vem se desenvolvendo e ampliando o seu escopo de atuação tanto para as atividades operacionais como as de serviço relacionadas ao abastecimento, transporte, distribuição, armazenagem e gerenciamento de demandas. A logística é a área da gestão responsável por prover recursos, equipamentos e informações para a execução de todas as atividades de uma empresa, e está intimamente ligada às ciências humanas (administração, economia, contabilidade, estatística, marketing, etc.) envolvendo diversos recursos da engenharia, tecnologia, transporte e recursos humanos. Fundamentalmente é dividida em dois tipos de atividades: Principais (transporte, gerenciamento de estoques, e processamento de pedidos); Secundárias (armazenagem, manuseio de materiais, embalagem, compras, programação de produtos e sistema de informação). Silva et al (2010) visualiza a logística, enquanto participante ativa do planejamento estratégico de qualquer organização, segundo quatro pilares interdependentes: infraestrutura (estrutura física, transportes, comunicações, energia, etc.); cadeia de suprimentos (integração no processo logístico, colaboração mútua); tecnologia (recursos - código de barras, tecnologia de informação - que otimizam a infraestrutura e as diversas cadeias de suprimentos); e pessoas (conhecimento para utilizar a tecnologia na movimentação da cadeia de suprimento dentro da infraestrutura).

A principal missão da logística é disponibilizar bens e serviços gerados por uma sociedade, nos locais, no tempo, nas quantidades e na qualidade em que são necessários aos utilizadores. Esta área do conhecimento tornou-se vital para o sucesso empresarial, dentro do atual cenário concorrencial, frente à necessidade de competição, cooperação e inovação decorrentes da introdução frequente de novos produtos e clientes sensíveis a serviços, requerendo velocidade de resposta, flexibilidade operacional e maior visibilidade das cadeias de suprimentos, cujo processo interliga fornecedores (empresas) desde a fonte inicial de matéria-prima até o ponto de consumo do produto acabado. Essa cadeia, conforme Leite (2010) engloba o planejamento e gestão de todas as atividades envolvidas na seleção das fontes de fornecimento, aquisição, transformação, e da gestão logística, incluindo a coordenação e colaboração de parcerias, quer sejam intermediários, terceiros ou clientes.

Com a entrada de novos mercados, uso de novas políticas e atividades estratégicas por parte das empresas, atualmente existe um aumento significativo nas quantidades e nas variedades das mercadorias produzidas e comercializadas, bem como na diminuição do ciclo de vida dos produtos, há uma necessidade do gerenciamento e retorno de componentes desses produtos ou até deles mesmo por completo ao inicio da cadeia logística. Assim, Leite (2010) informa que o retorno dos produtos de pós-venda e de pósconsumo pode refletir nas operações de rentabilidade das atividades das empresas, ao esgotar os sistemas tradicionais de disposição final, inclusive provocando poluição por contaminação ou por excesso. As legislações ambientais, visando à redução desse impacto, desobrigam gradativamente os governos e responsabilizam as empresas ou suas cadeias industriais, pelo equacionamento dos fluxos reversos dos produtos de pós-consumo que, na ausência, podem constituir em um risco à imagem da empresa, à sua reputação quanto à cidadania, consciência e responsabilidade socioambiental diante da comunidade.

\section{- LOGÍSTICA REVERSA}


Dentro de uma perspectiva estratégia integrada, a logística reversa refere-se às decisões no macro ambiente empresarial constituído pela sociedade, comunidades locais, governo e ambiente concorrencial, levando em consideração as características que garantirão competitividade e sustentabilidade às organizações nos eixos econômico e ambiental. Por sua vez, um aspecto operacional envolve o uso de ferramentas aplicadas, tal qual a caracterização do produto logístico em seus aspectos de relevância para as operações, origens e destinos, modelos de transportes, armazenagem, gestão de estoques, etc. Leite, (2010) entende por Logística Reversa a área da logística empresarial que planeja, opera e controla o fluxo e as informações logísticas correspondentes, do retorno dos bens de pósvenda e de pós-consumo ao ciclo de negócios ou ao ciclo produtivo, por meio de canais de distribuição reversos, agregando-lhes valores de diversas naturezas: econômico, prestação de serviços, imagem corporativa, ecológico-legal, etc. Já, o produto logístico é o conjunto de dimensões do produto que impactam diretamente nas decisões logísticas: valor agregado, peso, volume, geometria, riscos diversos, etc.

Pereira et al (2012) considera este ramo do saber que engloba o conceito tradicional de logística agregando um conjunto de ações ligadas desde a redução de matérias-primas até a destinação final correta de produtos, materiais e embalagens e consequente reuso, reciclagem ou produção de energia. A logística reversa também recebe os nomes de logística integral ou de logística inversa. Aliado ao escopo da Logística Reversa surge o termo Logística Verde, que procura compreender e minimizar os impactos ecológicos gerados pelas atividades logísticas, incluindo a medição do impacto ambiental gerado pelos meios de transporte, certificações, diminuição do consumo de energia, e redução do uso de materiais.

Enquanto o Canal de Distribuição Direto (CDD) refere-se ao fluxo dos produtos da cadeia de distribuição do mercado primário (da matéria-prima ao mercado consumidor), o Canal de Distribuição Reverso (CDR) amplia as atividades do fluxo direto incluindo o retorno, o reuso, a reciclagem e a disposição segura de seus componentes após o fim da vida útil, não conformidade, defeito, quebra ou inutilização (PEREIRA et al., 2012). Assim pode-se subdividir a logística reversa em dois tipos: pós-venda e pós-consumo. A Logística Reversa de Pós-Venda, é a área de atuação específica que se ocupa do equacionamento e da operacionalização do fluxo físico e das informações logísticas correspondentes de bens de pós-venda, não usados ou com pouco uso, os quais, por diferentes motivos, retornam aos diferentes elos da cadeia de distribuição direta, que se constituem de uma parte dos canais reversos pelos quais esses produtos fluem.

Por sua vez, a Logística Reversa de Pós-Consumo equaciona e operacionaliza igualmente o fluxo físico e as informações correspondentes de bens de pós-consumo descartados pela sociedade em geral, que retornam ao ciclo de negócios ou ao ciclo produtivo por meio de canais de distribuição reversos específicos. Seu objetivo específico é agregar valor ao produto logístico constituído por bens inservíveis ao proprietário original ou que ainda possuem condições de utilização, por produtos descartados pelo fato de terem chegado ao fim da vida útil e por resíduos industriais. Esses produtos de pós-consumo poderão se originar de bens duráveis ou descartáveis e fluir pelos canais reversos de reuso, remanufatura ou reciclagem, até a destinação final (LEITE, 2010).

- COLETA SELETIVA E GERENCIAMENTO DE RESÍDUOS 
A coleta ou recolha seletiva é o termo utilizado para o recolhimento dos materiais que são possíveis de serem reciclados (papéis, plásticos, metais e vidros), previamente separados na fonte geradora. A separação na fonte evita a contaminação dos materiais reaproveitáveis, aumentando o valor agregado destes e diminuindo os custos de reciclagem. Motta (2002) informa que, com as tecnologias atuais, apenas uma pequena parte dos resíduos urbanos não são passiveis de reaproveitamento, sendo direcionados para unidades de eliminação dos mesmos, normalmente os aterros sanitários.

A gestão de resíduos sólidos é considerada um serviço de interesse público de caráter essencial. Leite (2010) indica que a gestão integrada de resíduos deve ter como premissa o desenvolvimento sustentável. Para atingir tal meta é imprescindível que os planos adotem os conceitos dos "Três Erres" (Redução, Reutilização, Reciclagem) como padrões sustentáveis, e abordando os seguintes princípios: Precaução (nos casos de desconhecimento dos impactos negativos ao meio ambiente, quando há necessidade de tratamento e disposição de um resíduo sólido de característica desconhecida); Prevenção (nos casos em que os impactos ambientais já são conhecidos); e Poluidor Pagador (define os geradores de resíduos como responsáveis por todo o ciclo de seus resíduos, da geração à disposição final).

Esses aterros sanitários são grandes terrenos onde o lixo é depositado, comprimido e depois espalhado em camadas separadas por terra. Os incineradores, indicados para materiais de alto risco, reduzem seu volume, pois as cinzas ocupam menos espaço nos aterros e reduz-se o risco de poluição do solo, entretanto, podem liberar gases nocivos à saúde. Para Motta (2002). As usinas de compostagem transformam os resíduos orgânicos presentes no lixo em adubo, reduzindo o volume destinado aos aterros. Os resíduos sólidos urbanos, vulgarmente denominados por lixo urbano, são resultantes da atividade doméstica e comercial das povoações. A sua composição varia de população para população, dependendo da situação socioeconômica e das condições e hábitos de vida de cada um.

Os resíduos sólidos urbanos podem ser classificados das seguintes maneiras: Matéria orgânica: Restos de comida, da sua preparação e limpeza Papel e papelão: Jornais, revistas, caixas e embalagens Plásticos: Garrafas, garrafões, frascos, boiões e outras embalagens Vidro: Garrafas, frascos, copos Metais: Latas Outros: Roupas, óleos de cozinha e óleos de motor, resíduos informáticos. Existem também alguns tipos de resíduos diferentes dos comumente encontrados e que são denominados tóxicos. Estes necessitam de um destino especial para que não contaminem o ambiente e os seres que nele habitam, como aerossóis vazios, pilhas, baterias, lâmpadas fluorescentes, restos de medicamentos e outros.

A coleta dos resíduos urbanos pode ser indiferenciada ou seletiva. É indiferenciada quando não ocorre nenhum tipo de seleção na sua coleta e acabam rotulados como lixo comum. E é seletiva quando os resíduos são recolhidos já com os seus componentes separados de acordo com o tipo de resíduo e destino para o qual são enviados. Após a coleta, o lixo pode ser encaminhado para três lugares: um aterro sanitário, uma unidade de incineração ou uma unidade de valorização e tratamento de resíduos. No aterro sanitário, o lixo é jogado para que o solo absorva e decomponha seu conteúdo. Este é o destino mais comum para o lixo de coleta Indiferenciada, pois não necessita cuidados especiais e é uma forma de esgotar rapidamente a enorme quantidade de lixo gerado pelas metrópoles e outras grandes cidades. 
É para a unidade de incineração que são enviados os resíduos que não podem ou não devem ser jogados a céu aberto em um aterro. É o caso das pilhas, equipamentos eletrônicos e lixo hospitalar. Nessas unidades, o lixo é queimado e passa por alguns filtros antes de ser liberado no ambiente. Por ser um processo caro e lento, apenas uma pequena parcela dos resíduos (aqueles que foram citados anteriormente) pode passar por ele, o que resulta mais uma vez no despejo de lixo em Aterros Sanitários.

As Unidades de Valorização e Tratamento de Resíduos, ou, Unidades de Reciclagem, têm o objetivo único de reaproveitar embalagens, papel e similares num processo de limpeza e reestruturação. No caso dos resíduos orgânicos, ao final da esteira de seleção em uma usina de triagem de lixo, pode ser acrescentado um sistema de transformação, por reação química, destes materiais em um pó, totalmente estabilizado e livre de contaminantes, que podem ser usados como matéria prima de fabricação de artefatos de concreto com uma redução física de $50 \%$ de cimento e redução financeira de $70 \%$ dos custos de fabricação (MOTTA, 2002).

Os maiores beneficiados por esse sistema são o meio ambiente e a saúde da população. A reciclagem de papéis, vidros, plásticos e metais reduz a utilização dos aterros sanitários, prolongando sua vida útil. Se o programa de reciclagem contar, também, com uma usina de compostagem, os benefícios são ainda maiores. Além disso, a reciclagem implica uma redução significativa dos níveis de poluição ambiental e do desperdício de recursos naturais, através da economia de energia e matérias-primas. Iniciativas comunitárias ou empresariais podem reduzir os custos da prefeitura e mesmo produzir benefícios para as entidades ou empresas, além de contribuir positivamente para a imagem do governo e da cidade, a coleta seletiva exige um exercício de cidadania, no qual os cidadãos assumem um papel ativo em relação à sustentabilidade. Segundo Pereira (2012), os Hospitais devem ter planos de gerenciamento de resíduos aprovados pelos órgãos fiscalizadores competentes, contemplando não apenas os fatores estéticos e de controle de infecção hospitalar, mas também considerando as questões ambientais tão importantes para a geração atual e futura. As normas e resoluções existentes classificam os resíduos sólidos em função dos riscos potenciais ao meio ambiente e à saúde, e em função da natureza e origem.

A Lei de Política Nacional do Meio Ambiente (Lei $N^{\circ} 6.938 / 81$ ), no seu artigo $3^{\circ}$, e a Lei dos Crimes Ambientais (Lei № 9.605/98), artigos 54 e 56, responsabilizam administrativa, civil e criminalmente as pessoas físicas e jurídicas, autoras e coautoras de condutas ou atividades lesivas ao meio ambiente. Com isso, as fontes geradoras ficam obrigadas a adotar tecnologias mais limpas, aplicar métodos de recuperação e reutilização sempre que possível, estimular a reciclagem e dar destinação adequada, incluindo transporte, tratamento e disposição final.

\section{- CLASSIFICAÇÃO E TIPOS DE RESÍDUOS SÓLIDOS}

Resíduos sólidos e semissólidos são os resultantes de atividades de origem industrial, comercial, hospitalar, doméstica, agrícola, de serviços e de varrição, inclusive os lodos provenientes dos sistemas de tratamento de água e os gerados em equipamentos e instalações de controle de poluição. Conforme Severo, (2010). Uma pequena parcela dos serviços urbanos é composta de resíduos dos serviços de saúde, que representam uma das menores partes do total de resíduos gerados, entretanto apresentam potenciais riscos à saúde humana. Quanto aos riscos potenciais ao meio ambiente e à saúde pública, os resíduos do tipo A.1, Classe I denominados como perigosos, e são aqueles que, em função 
de suas propriedades físicas, químicas ou biológicas, podem apresentar riscos à saúde e ao meio ambiente. Eles possuem uma ou mais das seguintes propriedades: inflamabilidade, corrosividade, reatividade, toxicidade e patogenecidade.

Os resíduos do tipo A.2, Classe II são denominados de não perigosos, e são subdivididos em duas classes A.2.1, Classe II-A, são chamados de não inertes e podem ter as propriedades de biodegradabilidade, combustibilidade ou solubilidade em água, e os do tipo A.2.2, Classe II-B, que são nomeados de inertes e não apresentam nenhum de seus constituintes solubilizados a concentrações superiores aos padrões de potabilidade de água, com exceção dos aspectos cor, turbidez, dureza e sabor.

Quanto à origem e natureza, os resíduos sólidos podem ser do tipo: Domiciliar (B.1); Comercial, varrição e feiras livres (B.2); Serviços de saúde (B.3); Portos, aeroportos e terminais rodoviários e ferroviários (B.4); Industriais (B.5); Agrícolas (B.6); Construção civil (B.7). Com relação à responsabilidade pelo gerenciamento, são divididos em: Urbanos (C.1): resíduos domésticos ou residenciais (C.1.1); resíduos comerciais (C.1.2); resíduos públicos (C.1.3); Fontes especiais (C.2): resíduos industriais (C.2.1); resíduos da construção civil (C.2.2); rejeitos radioativos (C.2.3); resíduos de portos, aeroportos e terminais rodoferroviários (C.2.4); resíduos agrícolas (C.2.5); e em resíduos de serviços de saúde (C.2.6). (PEREIRA et al., 2012).

\section{- RESÍDUOS DE SERVIÇOS DE SAÚDE}

São definidos como geradores de Resíduos de Serviços de Saúde todos os serviços relacionados com o atendimento à saúde humana ou animal, incluindo todo e qualquer serviço de assistência domiciliar e de trabalhos de campo; laboratórios analíticos de produtos para a saúde; necrotérios, funerárias em geral, serviços de medicina legal, drogarias e farmácias inclusive as de manipulação; estabelecimentos de ensino e pesquisa na área da saúde, centro de controle de zoonoses; distribuidores de produtos farmacêuticos, importadores, distribuidores produtores de materiais e controles para diagnóstico in vitro, unidades móveis de atendimento à saúde; serviços de acupuntura, serviços de tatuagem, dentre outros similares. (RDC ANVISA No 306, 2004 e Resolução CONAMA No 358, 2005). Conforme a tabela 01, as mesmas normas classificam esses resíduos em cinco grupos:

Tabela 01: Classificação dos Resíduos dos Serviços de Saúde.

\begin{tabular}{|c|l|l|}
\hline GRUPO & \multicolumn{1}{|c|}{ DEFINIÇÃO } & \multicolumn{1}{c|}{ EXEMPLO } \\
\hline $\mathbf{A}$ & $\begin{array}{l}\text { Agentes biológicos que podem } \\
\text { apresentar risco de infecção. }\end{array}$ & $\begin{array}{l}\text { Placas e lâminas de laboratório, } \\
\text { carcaças, peças anatômicas (membros), } \\
\text { tecidos, bolsas transfusionais contendo } \\
\text { sangue, dentre outras. }\end{array}$ \\
\hline $\mathbf{B}$ & $\begin{array}{l}\text { Substâncias químicas que podem } \\
\text { apresentar risco à saúde pública ou } \\
\text { ao meio ambiente, (inflamabilidade, } \\
\text { corrosividade, reatividade e e } \\
\text { toxicidade). }\end{array}$ & $\begin{array}{l}\text { Medicamentos apreendidos, reagentes de } \\
\text { laboratório, resíduos contendo metais } \\
\text { pesados, dentre outros. }\end{array}$ \\
\hline $\mathbf{C}$ & $\begin{array}{l}\text { Materiais resultantes de atividades } \\
\text { humanas que } \\
\text { radionuclídeos em quantidades }\end{array}$ & $\begin{array}{l}\text { Produtos dos serviços de medicina } \\
\text { nuclear e radioterapia etc. }\end{array}$ \\
\hline
\end{tabular}




\begin{tabular}{|c|l|l|l|}
\hline \hline & \multicolumn{2}{l|}{ superiores aos limites de eliminação } \\
especificados. & \\
\hline D & $\begin{array}{l}\text { Não apresenta risco biológico, } \\
\text { químico ou radiológico à saúde ou } \\
\text { ao meio ambiente, e seus } \\
\text { componentes podem ser } \\
\text { equiparados aos resíduos } \\
\text { domiciliares. }\end{array}$ & $\begin{array}{l}\text { Sobras de alimentos e do preparo de } \\
\text { alimentos, resíduos das áreas } \\
\text { administrativas etc. }\end{array}$ \\
\hline E & $\begin{array}{l}\text { Materiais perfuro-cortantes ou } \\
\text { escarificantes. }\end{array}$ & $\begin{array}{l}\text { Lâminas de barbear, agulhas, ampolas de } \\
\text { vidro, pontas diamantadas, lâminas de } \\
\text { bisturi, lancetas, espátulas e outros } \\
\text { similares. }\end{array}$ \\
\hline
\end{tabular}

Pode-se compreender que os resíduos de serviços de saúde são parte importante do total de resíduos sólidos urbanos, não necessariamente pela quantidade gerada (cerca de $1 \%$ a $3 \%$ do total), mas pelo potencial de risco que representam à saúde e ao meio ambiente. Os estabelecimentos de saúde incrementam novas tecnologias incorporadas aos métodos de diagnósticos e tratamento, frente à evolução da ciência. Neste processo ocorre a geração de novos materiais, substâncias e equipamentos, com presença de componentes mais complexos e perigosos para quem os manuseia, e para o meio ambiente que os recebe.

Os resíduos do serviço de saúde merecem atenção especial em todas as suas fases de manejo (segregação, condicionamento, armazenamento, coleta, transporte, tratamento e disposição final) em decorrência dos imediatos e graves riscos que podem oferecer, por apresentarem componentes químicos, biológicos e radioativos. Esses resíduos representam um potencial de risco em duas situações: Para a saúde ocupacional de quem manipula esse tipo de resíduo, seja o pessoal ligado à assistência médica ou ao setor de limpeza e manutenção; Para o meio ambiente, como decorrência da destinação inadequada de qualquer tipo de resíduo. (PEREIRA, 2012).

O gerenciamento de resíduos dos serviços de saúde constitui-se no conjunto de procedimentos de gestão, planejados e implementados a partir de bases científicas, técnicas, normativas e legais, com o objetivo de minimizar a produção de resíduos. Como resultado do gerenciamento obtém-se o encaminhamento seguro dos resíduos e sua eficácia visa à proteção dos trabalhadores, à preservação da saúde pública, dos recursos naturais e do meio ambiente. O Plano de Gerenciamento dos Resíduos de Serviços de Saúde (PGRSS) tem por objetivo contribuir para a melhor segregação dos resíduos promovendo a redução do seu volume e diminuir a incidência de acidentes ocupacionais através de uma Educação Continuada. Visa estimular a reciclagem dos resíduos comuns para reduzir os custos com o manejo dos mesmos no cumprimento a legislação vigente. Objetiva também aumentar a vida útil dos aterros sanitários e valas sépticas otimizando a sua utilização, contribuindo para a proteção da saúde e do meio ambiente. (SEVERO, 2010).

A RDC ANVISA N N $^{\circ}$ 306/04 define que é da competência dos serviços geradores de Resíduos de Serviços de Saúde a elaboração do Plano de Gerenciamento de Resíduos de Serviços de Saúde (PGRSS) obedecendo a critérios técnicos, legislação ambiental, normas de coleta e transporte dos serviços locais de limpeza urbana e outras. Exige ainda a designação de profissional para exercer a função de Responsável pela elaboração e implantação do PGRSS e, da mesma forma, a indicação de responsável pela coordenação 
da execução do PGRSS. É um documento que descreve as ações relacionadas ao manejo dos resíduos, observando suas características e riscos dentro do estabelecimento, apontando e descrevendo as ações relativas ao manejo dos resíduos de serviço de saúde, observando suas características e riscos, relacionados ao estabelecimento de saúde e obrigando o gerador a prover a capacitação e o treinamento inicial e de forma continuada para o pessoal envolvido no gerenciamento de resíduos, bem como fazer constar nos termos de licitação e de contratação sobre os serviços as exigências de comprovação de capacitação e treinamento dos funcionários das firmas prestadoras de serviço de limpeza e conservação que pretendam atuar nos estabelecimentos de saúde, bem como no transporte, tratamento e disposição final destes resíduos, inclusive mantendo registro de operação de venda ou de doação dos resíduos destinados à reciclagem ou compostagem.

Na gestão de resíduos sólidos de serviços de saúde, os estabelecimentos prestadores de serviços de saúde podem contratar outros prestadores para realizar os serviços de limpeza, coleta de resíduos, tratamento, disposição final e comercialização de materiais recicláveis. Neste caso é de fundamental importância a verificação periódica se os procedimentos definidos e a conduta dos atores estão em sincronia com as leis. As contratações devem exigir e garantir que as empresas cumpram as legislações vigentes. Ao assegurar o cumprimento das legislações por parte de empresas terceirizadas, o gerador tem como responsabilizá-los em caso de irregularidades, tornando-os também responsáveis no caso de danos decorrentes da prestação destes serviços.

\section{METODOLOGIA}

O presente trabalho trata-se de uma investigação de natureza qualitativa, classificada como Estudo de caso, com caráter descritivo da realidade. Segundo Triviños (2012) o Estudo de Caso pode ser exploratório ao obter informação preliminar acerca do respectivo objeto de interesse, podendo ser descritivo quando tem como propósito descrever o caso em estudo. Assim, a pesquisa descritiva tem por finalidade observar, registrar e analisar os fenômenos sem entrar tanto no mérito de seu conteúdo e por outro lado, se aplica quando o pesquisador tem o interesse em observar a ocorrência do fenômeno no campo e não discuti-lo apenas do ponto de vista da teoria. Portanto, é uma investigação singular, que esmiúça uma situação específica procurando características e especificidades que possam contribuir para a compreensão do fenômeno de interesse.

Esta pesquisa pode ser ainda classificada como do tipo documental, pelos procedimentos ou meios, visto que envolve investigação com base em documentos ou relatórios presentes dentro da empresa. A análise documental constitui uma técnica importante na pesquisa qualitativa, seja complementando informações obtidas por outras técnicas, seja desvelando aspectos novos de um tema ou problema. É realizada a partir de documentos vigentes ou retrospectivos, considerados cientificamente autênticos, neste caso principalmente através de documentos legais (legislação) e pesquisa bibliográfica, pelo aporte na definição e resolução dos problemas já conhecidos, como também na exploração de novas perspectivas onde os mesmos ainda não se cristalizaram suficientemente, permitindo a produção de novas conclusões. (LUDKE e ANDRÉ, 1986).

\section{RESULTADOS}


O Plano de Gerenciamento dos Resíduos de Serviços de Saúde (PGRSS) da LIGA, conforme Tabela 02, foi implantado somente em 2011. São realizadas avaliações periódicas através do estudo de planilha de dados alimentada mensalmente para analisar a quantidade em quilogramas $(\mathrm{Kg})$ de resíduos que foram descartados em cada mês. É feita então uma comparação com os anos anteriores observando se houve um aumento ou diminuição da geração desses resíduos. Entre as causas de incremento atípico estão: mudança no manejo dos descartes dos RSS; férias do colaborador responsável; e mudança na estrutura física do hospital.

Tabela 02: Quantidade segregada de resíduos em quilogramas

\begin{tabular}{|c|c|c|c|c|}
\hline ANO & Policlínica & Hospital Luiz Antônio & CECAN & Total \\
\hline $\mathbf{2 0 1 1}$ & $\mathbf{3 6 0 2 5}$ & $\mathbf{5 6 7 5 0}$ & $\mathbf{1 8 9 5 0}$ & $\mathbf{1 1 1 7 5 0}$ \\
\hline $\mathbf{2 0 1 2}$ & $\mathbf{3 1 3 7 5}$ & $\mathbf{6 4 9 7 5}$ & $\mathbf{2 3 4 5 0}$ & $\mathbf{1 1 9 8 0 0}$ \\
\hline
\end{tabular}

Foi observado que este aumento de quantidade segregada é justificado em parte pelo com o crescimento que a empresa teve neste mesmo período. A unidade Policlínica apresentou redução dos seus resíduos em relação à melhoria, tivemos a Policlínica reduzindo os seus RSS, O CECAN estava reduzindo para uma quantidade abaixo de 2011 até a construção e operacionalização do setor de lavanderia. Já na unidade HLA aconteceram algumas mudanças em relação ao manejo solicitado pela Comissão de Controle de Infecção Hospitalar (CCIH), o que também contribuiu para seu incremento.

A previsão para o ano de 2013 é baixar a quantidade de resíduos no HLA e a manutenção no CECAN dos patamares de 2012, entretanto na POLICLÍNICA ocorrerá um aumento nos RSS devido à operacionalização do setor UNIPOL, composto por 29 leitos construídos em parceria com uma operadora de plano de saúde, que entraram em funcionamento no início daquele ano.

Quanto a variação da proporção de resíduos do Grupo A e E, de acordo com a Tabela 03, ocorreu um aumento de 3.650 quilos entre 2011 e 2012. E, quanto aos resíduos do Grupo B, verificou-se uma diminuição de 380,0 litros no mesmo período. O quadro abaixo mostra a quantidade de material reciclado no ano de 2012:

Tabela 03: Quantidade em quilogramas de material reciclado no ano de 2012

\begin{tabular}{|c|c|c|}
\hline PAPEL/PAPELÃO & PLÁSTICO & FERRO \\
\hline $\mathbf{4 3 8 0}$ & $\mathbf{2 8 9 5}$ & $\mathbf{1 8 1 5}$ \\
\hline
\end{tabular}

O principal problema apontado no gerenciamento dos RSS foi a conscientização dos trabalhadores da área da saúde. Após a implantação do PGRSS em 2011 observou-se que as capacitações realizadas durante 2011 e 2012 aos funcionários auxiliaram na tarefa de gerenciar adequadamente esses resíduos, bem como facilitou uma melhor assistência para sanar as dúvidas dos colaboradores da empresa. Neste período foram capacitados 200 colaboradores, a organização possui aproximadamente 1.300 funcionários, o que demonstra um longo horizonte de desafios. Vale salientar que nenhum funcionário foi treinado no período anterior à implantação do PGRSS. Essas capacitações foram voltadas 
principalmente aos colaboradores que trabalham diretamente com os RSS (higienização, técnicos de enfermagem e enfermeiros).

Não foi verificada a existência de nenhum programa de qualidade, de redução de custos, de redução de energia e água, ou de reutilização de embalagens. O que existe, na verdade, são ilhas de colaboradores que, muitas vezes por iniciativa própria, trabalham em prol da conscientização acerca da redução dos custos. Este fato vem aumentando em consequência da maior oferta de alguns treinamentos educacionais pelo aumento da sensibilização dos colaboradores acerca desta problemática. Cerca de $40 \%$ dos trabalhadores capacitados aceitaram a ideia de redução, tornando-se multiplicadores repassando aos pares (colegas) os temas discutidos e assumindo uma postura de vigilância a respeito dos aspectos da coleta seletiva, substituição por materiais recicláveis, e descarte e acondicionamento coreto nos recipientes apropriados. Sobre a caracterização dos aspectos ambientais, são gerados efluentes sanitários e hospitalares, sendo estes efluentes disseminados na rede de esgoto do município de Natal/RN. As águas residuais contêm basicamente matéria orgânica e mineral, em solução e em suspensão, assim como alta quantidade de bactérias e outros organismos patogênicos e não patogênicos.

O abastecimento de água é feito através de poço tubular e pela Companhia de Água e Esgotos do Rio Grande do Norte (CAERN), o uso da água tem como finalidade o abastecimento humano, sendo a água utilizada para os funcionários, pacientes, acompanhantes, limpeza da unidade e aguação de jardim.

O acondicionamento e manuseio de resíduos infectantes do Grupo A, (Figura 01) é feito em saco plástico impermeável e resistente, de cor branca leitosa, com simbologia específica ou em embalagem para perfuro cortantes. Usa-se este como forro de lixeira, de material rígido, com pedal para abertura da tampa, superfície interna lisa e cantos arredondados, resistente, lavável, que não apresente vazamentos e capacidade entre $20 \mathrm{e}$ 100 litros. As lixeiras são de cor branca são identificadas com o símbolo de resíduos infectantes e são submetidas à desinfecção no mínimo, diariamente.

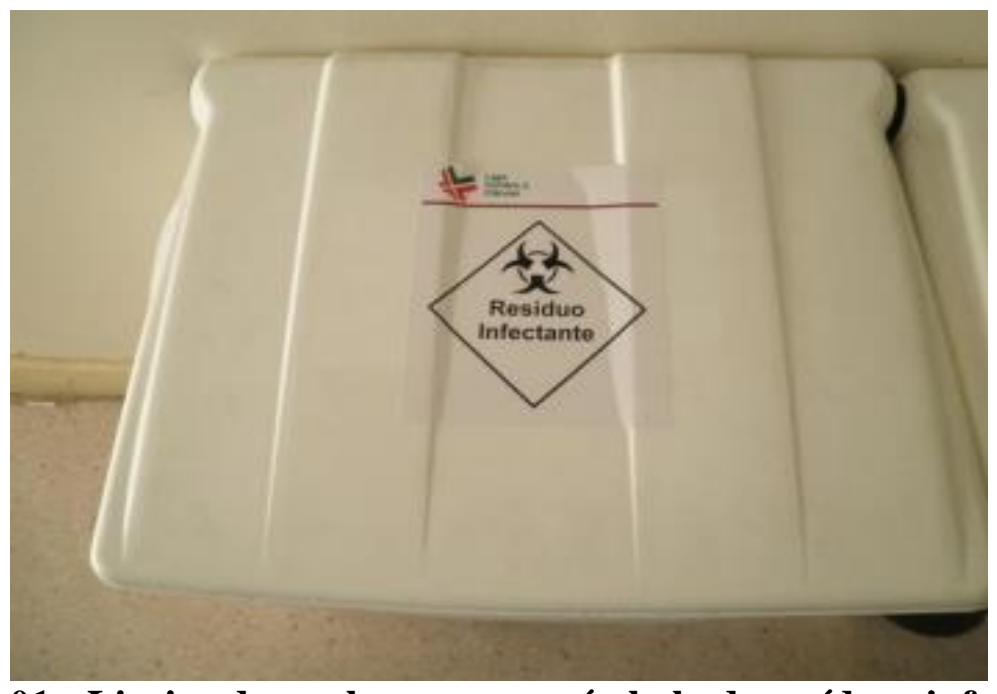

Figura 01 - Lixeira de cor branca com símbolo de resíduos infectantes

Os RSS infectantes e sem tratamento prévio, possui um acondicionamento que garante o não rompimento da embalagem ou usar duplo saco de cor branca leitosa, sendo um menor para conter os resíduos infectantes e outro maior para receber o primeiro, de forma que seja 
evitado o contato com seu lado externo e garanta maior segurança contra vazamentos; Os RSS são acondicionados em sacos plásticos de cor branca leitosa, onde é retirado o seu excesso de ar, sem inalar o conteúdo ou expor-se ao fluxo de ar interno. Os sacos plásticos são fechados totalmente, torcendo e amarrando sua abertura com nó, fecho plástico para lacre ou barbante, ao final de cada jornada de trabalho ou quando estiver com cerca de $2 / 3$ de seu volume preenchido.

Os resíduos do grupo E são acondicionados em recipientes rígidos, resistentes à punctura, ruptura ou vazamento, com tampa, devidamente identificados, (Figura 02) sendo expressamente proibido o esvaziamento destes recipientes para seu reaproveitamento. As agulhas descartáveis são desprezadas juntamente com as seringas, quando descartáveis, sendo proibido o reencape ou proceder sua retirada manualmente. Os recipientes acima descritos são descartados quando o preenchimento atingir $2 / 3$ de sua capacidade. Para os RSS do Grupo E, as embalagens são identificadas com o símbolo de risco biológico, acrescido da inscrição "Perfurocortantes".

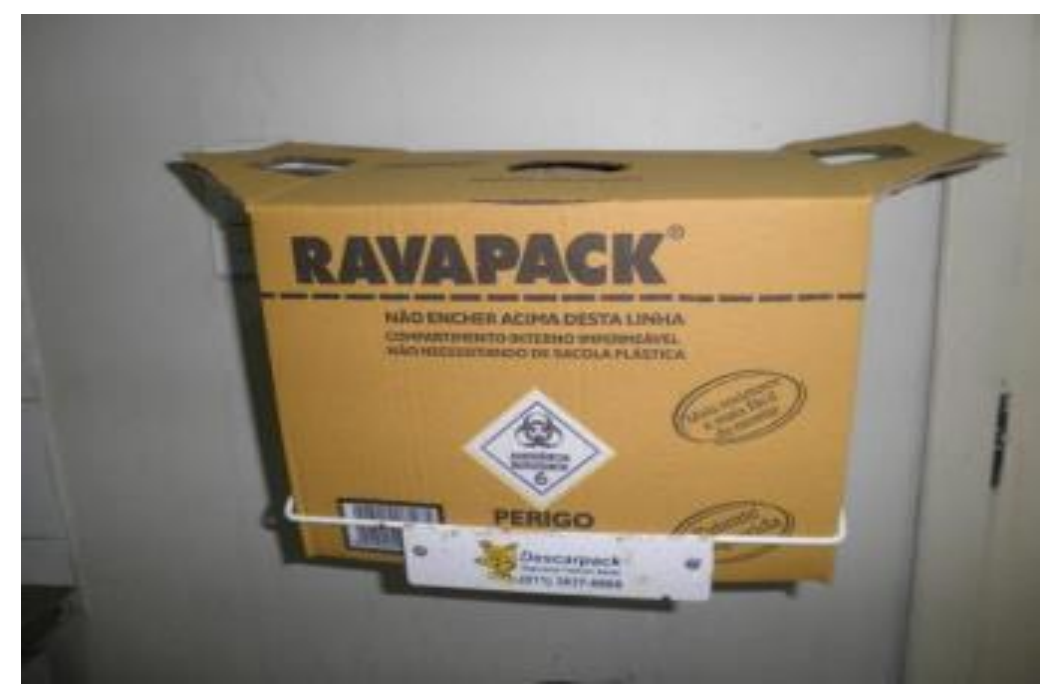

Figura 02 - Recipiente para Perfurocortantes

O uso de EPI (Figura 03) é feito pelos os funcionários, que lavam as mãos antes de vestir as luvas e depois de retirá-las. Após o manuseio dos RSS, são lavadas as mãos ainda enluvadas, em seguida, são retiradas as luvas e colocadas em local apropriado; Removemse imediatamente os RSS acondicionados para a sala de armazenamento intermediário; $\mathrm{O}$ procedimento de remoção é de forma para que não permita o rompimento das embalagens. No caso de acidente ou derramamento, é realizada imediatamente a limpeza e desinfecção do local, notificando a chefia da unidade. 


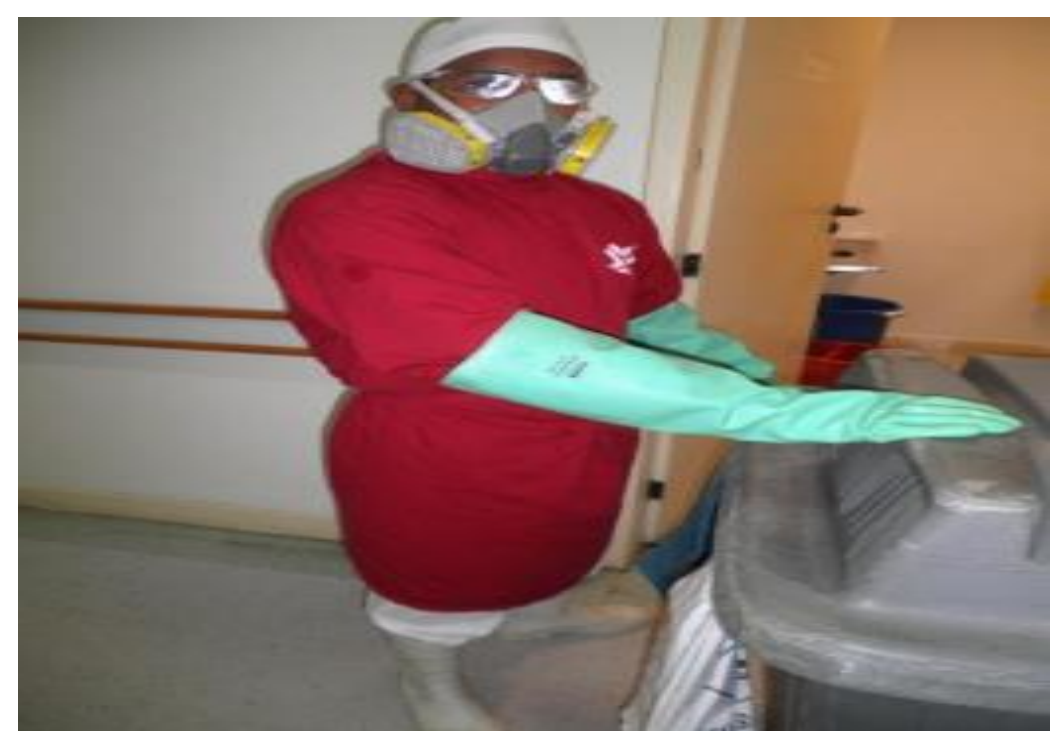

Figura 03 - Uso de EPIs pelos funcionários

Enquadram-se no grupo $\mathrm{C}$ os resíduos de rejeitos radioativos ou contaminados com radionuclídeos, provenientes de laboratórios de análises clínicas, serviços de medicina nuclear e radioterapia. Os rejeitos são compostos de seringas, agulhas, escalpes, luvas descartáveis, frascos contendo restos de radiofármacos, canudos plásticos, vestuário de pacientes que tenha se contaminado. A segregação do rejeito sólido é feita no Laboratório de Radiofármaco, onde possui um armário com oito gavetas blindadas com chumbo entre $5 \mathrm{~mm}$ e $10 \mathrm{~mm}$. Os rejeitos são afastados, fisicamente de quaisquer outros materiais, são segregados e acondicionados em recipientes adequados, os quais são identificados e classificados de acordo com a sua categoria.

Para o acondicionamento e manuseio de resíduos químicos do Grupo B, (Figura 04) são observadas as exigências de compatibilidade química dos resíduos entre si (ANVISA, RDC $n^{\circ} 306 / 2004$ ), assim como os materiais das embalagens de forma a evitar reações químicas; As embalagens são identificadas conforme NBR 7500. Os resíduos líquidos são acondicionados em recipientes de material compatível, resistentes, rígidos e estanques, com tampa rosqueada e vedante e identificadas com a discriminação da substância química e frases de risco.

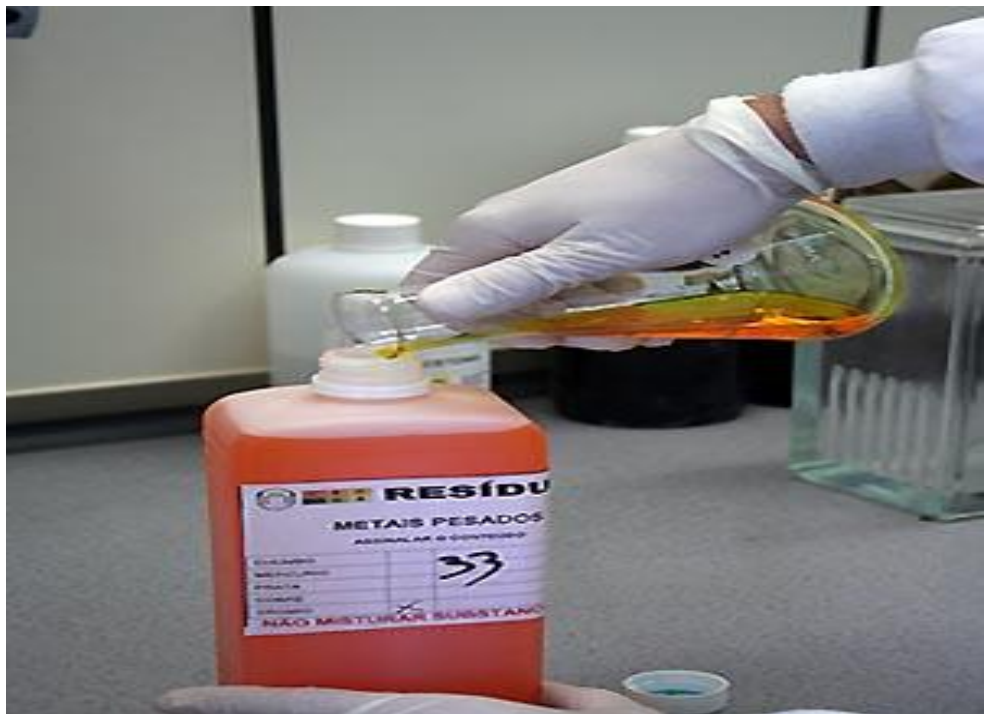

Figura 04: Manuseio de resíduos do grupo B 
Os resíduos sólidos (Figura 05) são acondicionados em recipientes de material rígido, adequados para cada tipo de substância química, respeitadas as características físicoquímicas e seu estado físico e identificadas; As embalagens secundárias não contaminadas pelo produto são fisicamente descaracterizadas e tratadas como resíduos do Grupo D. O acondicionamento e manuseio de resíduos comuns são feitos por padrões de cores, conforme normas técnicas da ABNT NBR N 9.190, e/ou são identificadas as lixeiras claramente com as simbologias para facilitar a identificação e manuseio de resíduo comum; Os resíduos comuns são manuseados separadamente, com seleção prévia dos componentes orgânicos, não recicláveis e recicláveis e acomodá-los em contentores estocados em abrigo próprio e exclusivo, com implantação de lixeiras identificadas e uso de lixeiras rígidas e de fácil limpeza.

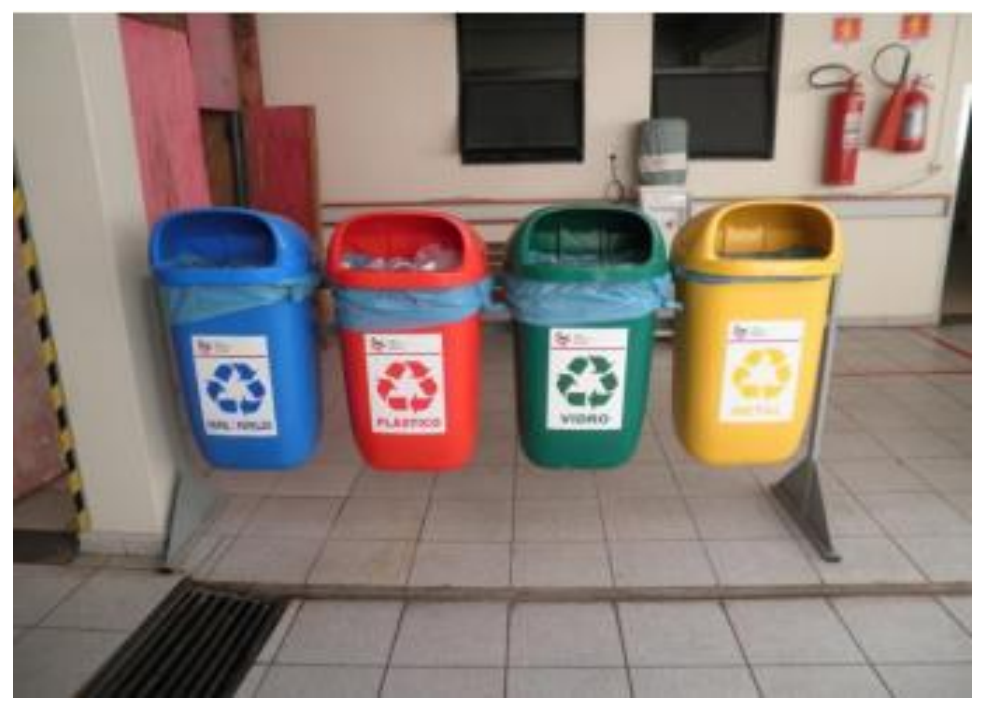

Figura 05 - Recipientes para acondicionamento de resíduos comuns

A identificação consiste no conjunto de medidas que permite o reconhecimento dos resíduos contidos nos sacos e recipientes, fornecendo informações ao correto manejo dos RSS. As identificações são apostas nos sacos de acondicionamento, nos recipientes de coleta interna e externa, nos recipientes de transporte interno e externo, e nos locais de armazenamento, em local de fácil visualização, de forma inapagável, utilizando-se símbolos, cores e frases, onde atendemos aos parâmetros referenciados na norma NBR 7.500 da $\mathrm{ABNT}$, além de outras exigências relacionadas à identificação de conteúdo e ao risco específico de cada grupo de resíduos.

As identificações dos sacos de armazenamento e dos recipientes de transporte são feitas por adesivos, onde são resistentes aos processos normais de manuseio dos sacos e recipientes. O Grupo A é identificado pelo símbolo de substância infectante constante na NBR-7500 da ABNT, com rótulos de fundo branco, desenho e contornos pretos. O Grupo B é identificado através do símbolo de risco associado, de acordo com a NBR 7500 da ABNT e com discriminação de substância química e frases de risco. O Grupo E é identificado pelo símbolo de substância infectante constante na NBR-7500 da ABNT, com rótulos de fundo branco, desenho e contornos pretos, acrescido da inscrição de RESÍDUO PERFUROCORTANTE, indicando o risco que apresenta o resíduo. Já o armazenamento intermediário (expurgo) consiste na guarda temporária dos recipientes contendo os resíduos já acondicionados, em local próximo aos pontos de geração, visando agilizar a 
coleta dentro do estabelecimento e otimizar o deslocamento entre os pontos geradores e o ponto destinado à apresentação para coleta externa.

A coleta e transporte internos consistem no traslado dos resíduos dos pontos de geração até local destinado ao armazenamento temporário ou armazenamento externo (Figura 06), com a finalidade de apresentação para a coleta. O transporte interno de resíduos é realizado atendendo roteiro previamente definido e em horários não coincidentes com a distribuição de roupas, alimentos e medicamentos, períodos de visita ou de maior fluxo de pessoas ou de atividades. É feito separadamente de acordo com o grupo de resíduos e em recipientes específicos a cada grupo de resíduos.

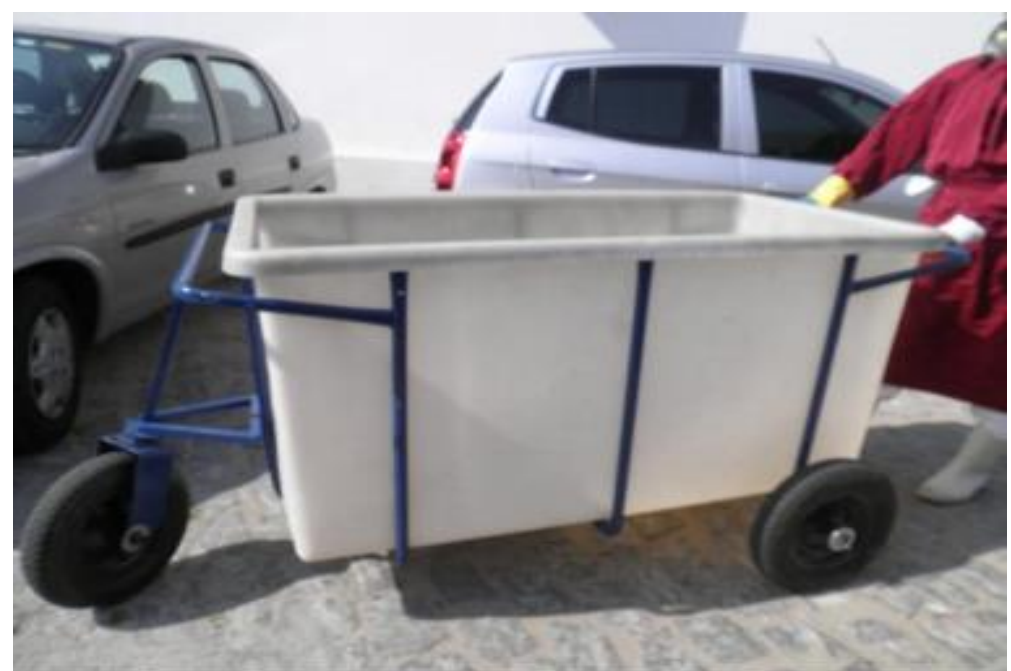

Figura 06 - Recipiente para transporte interno e externo

Os recipientes para transporte interno são constituídos de material rígido, lavável, impermeável, provido de tampa articulada ao próprio corpo do equipamento, cantos e bordas arredondadas, e são identificados com o símbolo correspondente ao risco do resíduo neles contidos. São providos de rodas revestidas de material que reduza o ruído. O uso de recipientes desprovidos de rodas obedece aos limites de carga permitidos para o transporte pelos trabalhadores, conforme normas reguladoras do Ministério do Trabalho e Emprego.

A sala para guarda de recipientes de transporte interno de resíduos, para o armazenamento final (Figura 07), possui pisos e paredes lisas e laváveis, sendo o piso resistente ao tráfego dos recipientes coletores. A sala de exclusividade de armazenamento de resíduos está identificada como "Sala de Resíduos". 


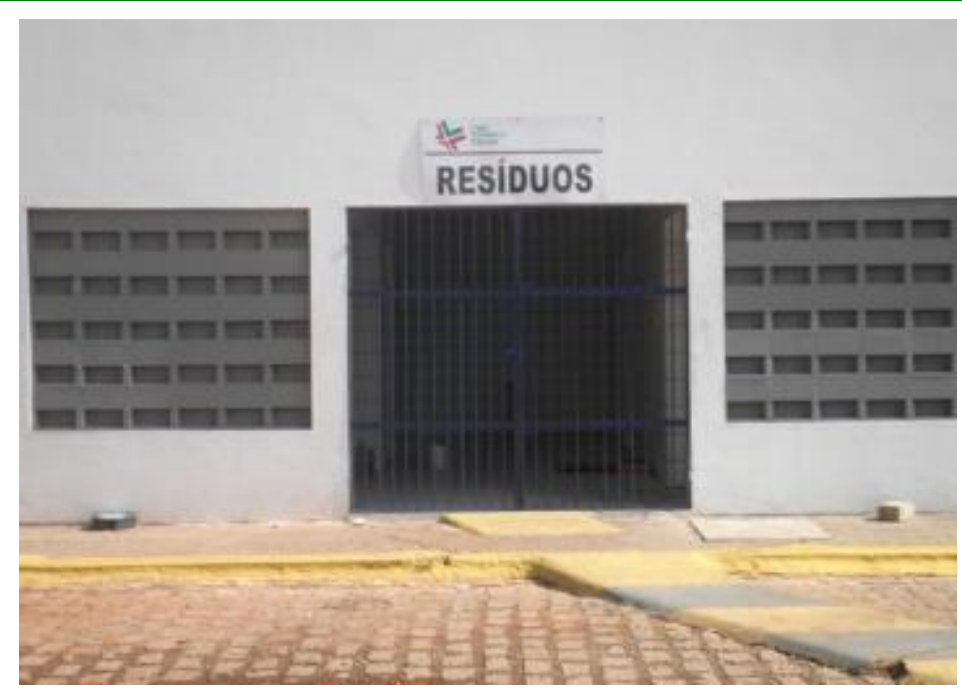

Figura 07 - Local para armazenamento dos resíduos

A LIGA faz um acompanhamento consolidado (Tabelas 04 a 09) quanto à classificação, caracterização, segregação, quantificação e acondicionamento dos resíduos de serviços de saúde segundo cada unidade, bem como os pontos de geração e o manejo externo para coleta, transporte e destinação final.

Tabela 04: Quantificação dos RSS em Kglmês do CECAN - 2012

\begin{tabular}{|c|c|c|c|c|c|c|c|c|c|c|c|}
\hline \multicolumn{10}{|c|}{ Quantificação dos Resíduos A } \\
\hline Jan & Fev & Mar & Abr & Mai & Jun & Jul & Ago & Set & Out & Nov & Dez \\
\hline 1375 & 1525 & 1700 & 1400 & 2000 & 2100 & 2450 & 2750 & 1850 & 2200 & 2025 & 2075 \\
\hline \multicolumn{10}{|c|}{ Quantificação dos Resíduos B } \\
\hline Jan & Fev & Mar & Abr & Mai & Jun & Jul & Ago & Set & Out & Nov & Dez \\
\hline 200 & - & 200 & 200 & 150 & 400 & - & 200 & - & - & 200 & - \\
\hline \multicolumn{10}{|c|}{ Quantificação dos Resíduos D (Papel-Papelão) } \\
\hline Jan & Fev & Mar & Abr & Mai Jun & Jul & Ago & Set & Out & Nov & Dez \\
\hline 595 & 720 & 210 & 486 & 210 & 290 & 387 & 480 & 465 & 195 & 515 & 380 \\
\hline \multicolumn{10}{|c|}{ Quantificação dos Resíduos D (Plástico) } \\
\hline Jan & Fev & Mar & Abr & Mai & Jun & Jul & Ago & Set & Out & Nov & Dez \\
\hline 40 & 75 & 46 & 20 & 40 & 43 & 25 & 50 & 15 & - & 30 & 40 \\
\hline \multicolumn{10}{|c|}{ Quantificação dos Resíduos D (Ferro) } \\
\hline Jan & Fev & Mar & Abr & Mai & Jun & Jul & Ago & Set & Out & Nov & Dez \\
\hline- & 70 & - & 30 & 30 & 50 & - & 40 & - & - & 40 & - \\
\hline \multicolumn{10}{|c|}{ Quantificação dos Resíduos D (Chumbo) } \\
\hline Jan & Fev & Mar Abr & Mai & Jun & Jul & Ago & Set & Out & Nov & Dez \\
\hline 189 & - & 213 & - & 30 & - & - & - & - & - & - & - \\
\hline
\end{tabular}

Tabela 05: Quantificação dos RSS em Kglmês da Policlínica - 2012

\begin{tabular}{|c|c|c|c|c|c|c|c|c|c|c|c|}
\hline \multicolumn{10}{|c|}{ Quantificação dos Resíduos A } \\
\hline Jan & Fev & Mar & Abr & Mai & Jun & Jul & Ago & Set & Out & Nov & Dez \\
\hline 2875 & 2225 & 2775 & 2600 & 2800 & 2350 & 2625 & 2925 & 2550 & 2425 & 2475 & 2750 \\
\hline \multicolumn{11}{|c|}{ Quantificação dos Resíduos B } \\
\hline
\end{tabular}




\begin{tabular}{|c|c|c|c|c|c|c|c|c|c|c|c|}
\hline \hline Jan & Fev & Mar & Abr & Mai & Jun & Jul & Ago & Set & Out & Nov & Dez \\
\hline 240 & - & - & 40 & - & - & - & 60 & - & - & - & 130 \\
\hline \multicolumn{10}{|c|}{ Quantificação dos Resíduos D (Papel-Papelão) } \\
\hline Jan & Fev & Mar & Abr & Mai & Jun & Jul & Ago & Set & Out & Nov & Dez \\
\hline 695 & 530 & 555 & 325 & 300 & 355 & 300 & 535 & - & 410 & 285 & 645 \\
\hline \multicolumn{10}{|c|}{ Quantificação dos Resíduos D (Plástico) } \\
\hline Jan & Fev & Mar & Abr & Mai & Jun & Jul & Ago & Set & Out & Nov & Dez \\
\hline 265 & 235 & 285 & 210 & 155 & 180 & 130 & 310 & - & 140 & 120 & - \\
\hline \multicolumn{10}{|c|}{ Quantificação dos Resíduos D (Ferro) } \\
\hline Jan & Fev & Mar & Abr & Mai & Jun & Jul & Ago & Set & Out & Nov & Dez \\
\hline- & - & - & - & - & - & - & 355 & - & - & - & - \\
\hline
\end{tabular}

Tabela 06: Quantificação dos RSS em Kg|mês do Hospital Luiz Antônio - 2012

\begin{tabular}{|r|c|c|c|c|c|c|c|c|c|c|c|}
\hline \multicolumn{10}{|c|}{ Quantificação dos Resíduos A e E } \\
\hline Jan & Fev & Mar & Abr & Mai & Jun & Jul & Ago & Set & Out & Nov & Dez \\
\hline 4925 & 5575 & 6175 & 5625 & 5150 & 5475 & 5550 & 5800 & 4675 & 5400 & 5500 & 5125 \\
\hline \multicolumn{10}{|c|}{ Quantificação dos Resíduos B } \\
\hline Jan & Fev & Mar & Abr & Mai & Jun & Jul & Ago & Set & Out & Nov & Dez \\
\hline 680 & 400 & 400 & 600 & 580 & - & 800 & - & 600 & 600 & 600 & 600 \\
\hline \multicolumn{10}{|c|}{ Quantificação dos Resíduos D (Papel-Papelão) } \\
\hline Jan & Fev & Mar & Abr & Mai & Jun & Jul & Ago & Set & Out & Nov & Dez \\
\hline 505 & 480 & 895 & 365 & 260 & 240 & 510 & 180 & - & 505 & 240 & 200 \\
\hline \multicolumn{10}{|c|}{ Quantificação dos Resíduos D (Plástico) } \\
\hline Jan & Fev & Mar & Abr & Mai & Jun & Jul & Ago & Set & Out & Nov & Dez \\
\hline 265 & 330 & 615 & 355 & 140 & 140 & 285 & 150 & - & 270 & 205 & 140 \\
\hline \multicolumn{10}{|c|}{ Quantificação dos Resíduos D (Ferro) } \\
\hline Jan & Fev & Mar & Abr & Mai & Jun & Jul & Ago & Set & Out & Nov & Dez \\
\hline- & - & - & 1135 & - & - & 325 & 355 & - & - & - & - \\
\hline
\end{tabular}

Tabela 07: Classificação, Segregação dos RSS dos setores da Unidade CECAN. 


\begin{tabular}{|c|c|c|}
\hline Pontos de Geração & $\begin{array}{l}\text { Classe de } \\
\text { Resíduos }\end{array}$ & $\begin{array}{l}\text { Manejo Extra-Unidade } \\
\text { (Coleta, Transporte e Destinação Final) }\end{array}$ \\
\hline \multirow{3}{*}{ Braquiterapia } & Grupo A & Stericycle Brasil \\
\hline & Grupo D & Coleta urbana \\
\hline & Grupo E & Stericycle Brasil \\
\hline \multirow{3}{*}{ Ambulatório } & Grupo A & Stericycle Brasil \\
\hline & Grupo D & Coleta urbana \\
\hline & Grupo E & Stericycle Brasil \\
\hline \multirow{3}{*}{ Consultórios } & Grupo A & Stericycle Brasil \\
\hline & Grupo D & Coleta urbana \\
\hline & Grupo E & Stericycle Brasil \\
\hline Depecom e SESMT & Grupo D & Natal Reciclagem e Canassé Resíduos Potiguar \\
\hline \multirow{3}{*}{$\begin{array}{l}\text { Central de Material } \\
\text { de Esterilização }\end{array}$} & Grupo A & Stericycle Brasil \\
\hline & Grupo D & Coleta urbana \\
\hline & Grupo E & Stericycle Brasil \\
\hline Administração & Grupo D & Natal Reciclagem e Canassé Resíduos Potiguar \\
\hline Recepção & Grupo D & Natal Reciclagem e Canassé Resíduos Potiguar \\
\hline Digitação de laudos & Grupo D & Natal Reciclagem e Canassé Resíduos Potiguar \\
\hline Entrega de exames & Grupo D & Natal Reciclagem e Canassé Resíduos Potiguar \\
\hline \multirow{3}{*}{ Farmácia Central } & Grupo B & Stericycle Brasil \\
\hline & Grupo D & Natal Reciclagem e Canassé Resíduos Potiguar \\
\hline & Grupo E & Stericycle Brasil \\
\hline \multirow[t]{2}{*}{ Manutenção } & Grupo B & Brasóleo \\
\hline & Grupo D & Natal Reciclagem e Canassé Resíduos Potiguar \\
\hline \multirow[t]{2}{*}{ Nutrição } & Grupo D & Natal Reciclagem e Canassé Resíduos Potiguar \\
\hline & Grupo D & Coleta urbana \\
\hline \multirow{3}{*}{ Medicina nuclear } & Grupo A & Stericycle Brasil \\
\hline & Grupo C & Stericycle Brasil \\
\hline & Grupo E & Stericycle Brasil \\
\hline \multirow[t]{2}{*}{ Quimioterapia } & Grupo A & Stericycle Brasil \\
\hline & Grupo E & Stericycle Brasil \\
\hline \multirow[t]{2}{*}{ Radioterapia } & Grupo A & Stericycle Brasil \\
\hline & Grupo E & Stericycle Brasil \\
\hline Almoxarifado & Grupo D & Natal Reciclagem; Canassé Resíduos Potiguar \\
\hline
\end{tabular}

Tabela 08: Classificação, Segregação dos RSS dos setores da Unidade Policlínica 


\begin{tabular}{|c|c|c|}
\hline $\begin{array}{l}\text { Pontos de } \\
\text { Geração }\end{array}$ & $\begin{array}{l}\text { Classe de } \\
\text { Resíduos }\end{array}$ & $\begin{array}{l}\text { Manejo Extra-Unidade } \\
\text { (Coleta, Transporte e Destinação Final) }\end{array}$ \\
\hline \multirow{2}{*}{$\begin{array}{l}\text { U.T.I. } \\
\text { Centro cirúrgico }\end{array}$} & Grupo A & Stericycle Brasil \\
\hline & Grupo E & Stericycle Brasil \\
\hline \multirow{3}{*}{$\begin{array}{l}\text { Ambulatórios } \\
\text { Consultórios } \\
\text { Enfermarias }\end{array}$} & Grupo A & Stericycle Brasil \\
\hline & Grupo D & Coleta urbana \\
\hline & Grupo E & Stericycle Brasil \\
\hline \multirow{3}{*}{$\begin{array}{l}\text { Central de Material } \\
\text { de Esterilização }\end{array}$} & Grupo A & Stericycle Brasil \\
\hline & Grupo D & Coleta urbana \\
\hline & Grupo E & Stericycle Brasil \\
\hline Administração & Grupo D & Natal Reciclagem e Canassé Resíduos Potiguar \\
\hline Recepção & Grupo D & Natal Reciclagem e Canassé Resíduos Potiguar \\
\hline Entrega de exames & Grupo D & Natal Reciclagem e Canassé Resíduos Potiguar \\
\hline \multirow{3}{*}{ Farmácia Central } & Grupo B & Stericycle Brasil \\
\hline & Grupo D & Natal Reciclagem e Canassé Resíduos Potiguar \\
\hline & Grupo E & Stericycle Brasil \\
\hline \multirow[t]{2}{*}{ Manutenção } & Grupo B & Brasóleo \\
\hline & Grupo D & Natal Reciclagem e Canassé Resíduos Potiguar \\
\hline \multirow[t]{2}{*}{ Nutrição } & Grupo D & Natal Reciclagem e Canassé Resíduos Potiguar \\
\hline & Grupo D & Coleta urbana \\
\hline Radiologia & Grupo B & Brasóleo \\
\hline Almoxarifado & Grupo D & Natal Reciclagem e Canassé Resíduos Potiguar \\
\hline
\end{tabular}


Tabela 09: Classificação, Segregação dos RSS da Unidade Hospital Luiz Antônio

\begin{tabular}{|c|c|c|}
\hline $\begin{array}{l}\text { Pontos de } \\
\text { Geração }\end{array}$ & $\begin{array}{l}\text { Classe de } \\
\text { Resíduos }\end{array}$ & $\begin{array}{l}\text { Manejo Extra-Unidade } \\
\text { (Coleta, Transporte e Destinação Final) }\end{array}$ \\
\hline $\begin{array}{l}\text { Agência } \\
\text { Transfusional }\end{array}$ & Grupo A & Stericycle Brasil \\
\hline \multirow{3}{*}{$\begin{array}{l}\text { Ambulatórios, } \\
\text { Enfermarias }\end{array}$} & Grupo A & Stericycle Brasil \\
\hline & Grupo D & Coleta urbana \\
\hline & Grupo E & Stericycle Brasil \\
\hline \multirow{3}{*}{$\begin{array}{l}\text { Consultórios } \\
\text { Cabeça e Pescoço }\end{array}$} & Grupo A & Stericycle Brasil \\
\hline & Grupo D & Coleta urbana \\
\hline & Grupo E & Stericycle Brasil \\
\hline \multirow{3}{*}{$\begin{array}{l}\text { Central de Material de } \\
\text { Esterilização }\end{array}$} & Grupo A & Stericycle Brasil \\
\hline & Grupo D & Coleta urbana \\
\hline & Grupo E & Stericycle Brasil \\
\hline Administração & Grupo D & Natal Reciclagem e Canassé Resíduos Potiguar \\
\hline Recepção & Grupo D & Natal Reciclagem e Canassé Resíduos Potiguar \\
\hline Digitação de laudos & Grupo D & Natal Reciclagem e Canassé Resíduos Potiguar \\
\hline Entrega de exames & Grupo D & Natal Reciclagem e Canassé Resíduos Potiguar \\
\hline \multirow{3}{*}{ Farmácia Central } & Grupo B & Stericycle Brasil \\
\hline & Grupo D & Natal Reciclagem e Canassé Resíduos Potiguar \\
\hline & Grupo E & Stericycle Brasil \\
\hline \multirow{2}{*}{$\begin{array}{l}\text { Farmácia } \\
\text { de Manipulação }\end{array}$} & Grupo B & Stericycle Brasil \\
\hline & Grupo D & Natal Reciclagem e Canassé Resíduos Potiguar \\
\hline \multirow[t]{2}{*}{ Manutenção } & Grupo B & Brasóleo \\
\hline & Grupo D & Natal Reciclagem e Canassé Resíduos Potiguar \\
\hline \multirow{2}{*}{$\begin{array}{l}\text { Laboratório } \\
\text { de Patologia }\end{array}$} & Grupo A & Stericycle Brasil \\
\hline & Grupo B & Brasóleo \\
\hline \multirow[t]{2}{*}{ Nutrição } & Grupo D & Natal Reciclagem e Canassé Resíduos Potiguar \\
\hline & Grupo D & Coleta urbana \\
\hline \multirow{2}{*}{$\begin{array}{l}\text { Centro Cirúrgico } \\
\text { Clínica de Suporte } \\
\text { Oncológico } \\
\text { Pequena cirurgia }\end{array}$} & Grupo A & Stericycle Brasil \\
\hline & Grupo E & Stericycle Brasil \\
\hline \multirow[t]{2}{*}{ Quimioterapia } & Grupo A & Stericycle Brasil \\
\hline & Grupo E & Stericycle Brasil \\
\hline Radiologia & Grupo B & Brasóleo \\
\hline Almoxarifado & Grupo D & Natal Reciclagem e Canassé Resíduos Potiguar \\
\hline
\end{tabular}

\section{CONSIDERAÇÕES FINAIS}

Atualmente o gerenciamento integrado dos resíduos de serviços de saúde vem se constituindo objeto de debates, estudos e pesquisas, pelos desafios de operacionalização de sistemas adequados a cada tipo de organização. É fundamental uma gestão integrada, planejada e implantada a partir de bases científicas e técnicas, normativas e legais.

A Liga Norte Riograndense Contra o Câncer dispõe de um Plano de Gerenciamento de Resíduos dos Serviços de Saúde (PGRSS) condizente com seu porte e complexidade 
organizacional, implantado recentemente, e parte por esse motivo, ainda se caracteriza timidamente em relação a alguns aspectos. A empresa apresenta uma baixa quantidade de colaboradores capacitados de forma continuada, quando comparada com o total de funcionários da organização. Estes treinamentos não têm sensibilizado, nem estimulado de forma adequada à conscientização acerca desta temática, resumindo-se a boa vontade de alguns multiplicadores educacionais.

A ausência do coordenador técnico responsável pelo gerenciamento do PGRSS por motivos diversos, tais quais férias, licença ou viajem, chega a ponto de afetar até as quantidades usuais dos materiais reciclados, o que evidencia na prática uma sobrecarga e concentração de funções e competências em poucas pessoas, sendo necessária uma maior delegação de funções a esse respeito.

Fica subentendido que sobressai a necessidade de cumprimento das exigências legais vigentes dos órgãos fiscalizadores, do que em relação à micropolítica da conscientização cidadã, o que demonstra um longo caminho para por em prática o que se inclui no papel, a fim de uma adequada operacionalização de todas as demandas exigidas.

Um dos diversos dilemas quanto à gestão eficiente do manejo dos resíduos dos serviços de saúde é conciliar a demanda crescente por produtos e serviços geradores de resíduos, consequente às exigências da modernidade, com a necessidade veemente de redução requisitada pelo debate sempre atual da sustentabilidade.

\section{REFERÊNCIAS BIBLIOGRÁFICAS}

1. ANVISA. Resolução RDC n³3, de 25 de fevereiro de 2003.

2. ANVISA. Resolução RDC no 306, de 7 de dezembro de 2004 D.O.U. 10/12/2004.

3. BRASIL. M. S. ANVISA. Manual de gerenciamento de resíduos de serviços de saúde. Brasília: Ministério da Saúde, 2006. 182 p. (Série A. Normas e Manuais Técnicos).

4. CARVALHO, J. Logística. $3^{\mathrm{a}}$ ed. Lisboa: Edições Silabo, 2002.

5. CONAMA. Resolução no 358, de 29 de abril de 2005.

6. CONAMA. Resolução $n^{\circ} 20$, de 18 de junho de 1986.

7. GIL, A. C. Estudo de caso. São Paulo: ATLAS, 2009. 168p.

8. LEITE, P. R. Logística reversa: meio ambiente e competitividade. São Paulo: Pearson Prentice Hall, 2010.

9. LIGA NORTE RIOGRANDENSE CONTRA O CÂNCER. Plano de gerenciamento de resíduos de serviço de saúde (PGRSS - 2013/2014). Mimeo. 40p.

10. LIGA NORTE RIOGRANDENSE CONTRA O CÂNCER. Relatório anual. NatalRN, 2013. 62p.

11. LÜDKE, M., ANDRÉ, M.E.D.A. Pesquisa em educação: abordagens qualitativas. São Paulo: EPU, 1986.

12. MOTTA, M. L. A., ABREU, M. F. Experiências de Coleta Seletiva. Editora Petrópolis: Rio de Janeiro, 2002. 
13. MARTINS, M. A. H. Metodologia da pesquisa. Disponível em: <http://mariaalicehof5.vilabol.uol.com.br/>. Acesso em: 06.jun.2011.

14. PEREIRA, A. L. et al. Logística reversa e sustentabilidade. São Paulo: CENGAGE Learning, 2012.

15. SEVERO, A. A. Análise do gerenciamento ambiental nos hospitais de Caxias do Sul - RS. Universidade de Caxias do Sul. Dissertação de Mestrado. 2010. 121p.

16. SILVA, R. B. et al. Logística em organizações de saúde. Rio de Janeiro: FGV, 2010.

17. TRIVINOS, A. Introdução à Pesquisa em Ciências Sociais: A Pesquisa Qualitativa em Educação. São Paulo: Atlas, 2012.

18. VIVALDINI, M., PIRES, S. Operadores logísticos: integrando operações em cadeias de suprimento. São Paulo: Atlas, 2010.

19. YIN, R. K. Estudo de caso: planejamento e métodos. São Paulo: BOOKMAN COMPANHIA ED, 2005. 